\title{
Faktor yang Berhubungan dengan Kesadaran Keselamatan dan Kesehatan Kerja di Lingkungan Lanud Maimun Saleh Sabang
}

\author{
Factors Associated with Awareness of Occupational Safety and Health in The \\ Environment of Maimun Saleh Sabang Airport
}

\author{
Hendri Priatna ${ }^{1}$, Fauziah Andika ${ }^{* 2}$ \\ ${ }^{1,2}$ Program Studi Ilmu Kesehatan Masyarakat, Universitas Ubudiyah Indonesia, Kota Banda Aceh, Indonesia \\ *Korespondensi Penulis: fauziah@uui.ac.id
}

\begin{abstract}
Abstrak
Masalah adanya kasus kecelakaan maupun kecelakaan kerja, hal ini tentu saja harus dapat menjadi perhatian dari manajemen kesehatan dan keselamatan kerja di Lanud Maimun Saleh agar dapat meminimalisir lagi kasus terjadinya kecelakaan maupun penyakit yang diakibatkan oleh kelalaian dan lingkungan kerja sehingga kesehatan setiap personil dapat terpelihara dengan baik. Tujuan penelitian ini adalah Untuk mengetahui faktor yang berhubungan dengan kesadaran keselamatan dan kesehatan kerja di lingkungan Lanud Maimun Saleh Sabang. Penelitian ini bersifat analitik dengan pendekatan Cross Sectional. Pengumpulan data dilakukan, pada tanggal 22 s/d 25 November 2017. Sampel dalam penelitian ini adalah seluruh personil Lanud Maimun Saleh sebanyak 47 orang. pengambilan dengan cara total sampling Pengumpulan data dilakukan dengan cara wawancara selanjutnya dilakukan dengan uji chi-square. Dari hasil penelitian ini menunjukan bahwa dari hasil univariat kesadaran personil terhadap keselamatan dan keseahatan kerja yang tinggi 27 orang $(57,4 \%)$, perilaku positif 25 orang $(53,2 \%)$, lingkungan kerja baik 29 orang $(61,7 \%)$, perilaku $(\mathrm{p}$-value $=0,002)$, lingkungan $(\mathrm{p}$-value $=0,020)$. Ada hubungan antara prilaku dan lingkungan dengan kesadaran keselamatan dan kesehatan kerja di lingkungan Lanud Maimun Saleh Sabang. Diharapkan dapat memberikan informasi kepada personilnya agar berhati-hati dalam menjaga dirinya keselematan dan kesehatan kerja.
\end{abstract}

Kata kunci: kesadaran keselamatan dan kesehatan kerja, perilaku, lingkungan

\section{Abstract}

The problem of accidents and accidents, of course, should be the concern of health and safety management in Lanud Maimun Saleh in order to minimize the case of accidents and diseases caused by negligence and work environment so that the health of each personnel can well maintained. The objective is to know the factors related to awareness of occupational safety and health in Lanud Maimun Saleh Sabang. Analytical with cross sectional approach. Data collection was conducted, on 22 - 25 November 2017. The sample in this research is all personnel of Maimun Saleh airforce as many as 47 people. taking by total sampling. Data collecting is done by next interview done by chi-square test. research: From the result of this research show that from univariate result of personnel awareness to safety and high working degree 27 people $(57,4 \%)$, positive behavior 25 people $(53,2 \%)$, work environment good 29 people $(61,7 \% \%)$. bivariate behavior $(p$-value $=0.002)$, environment $(p$-value $=0.020)$. There is a relationship between behavior and environment with awareness of occupational 
safety and health in Lanud Maimun Saleh Sabang. It is expected to provide information to its personnel to be careful in maintaining his safety and occupational health.

Keywords: awareness of occupational safety and health, behavior, environment

\section{PENDAHULUAN}

Keselamatan dan kesehatan kerja (K3) merupakan upaya untuk menciptakan suasana bekerja yang am an, nyaman dan mencapai tujuan yaitu produktivitas setinggi-tingginya. Kesehatan dan Keselamatan Kerja sangat penting untuk dilaksanakan pada semua bidang pekerjaan tanpa terkecuali proyek pembangunan gedung seperti apartemen, hotel, mall dan lain-lain, karena penerapan K3 dapat mencegah dan mengurangi resiko terjadinya kecelakaan maupun penyakit akibat melakukan kerja. Smith dan Sonesh (2011) mengemukakan bahwa pelatihan keselamatan dan kesehatan kerja (K3) mampu menurunkan resiko terjadinya kecelakaan kerja. Semakin besar pengetahuan karyawan akan K3 maka semakin kecil terjadinya resiko kecelakaan kerja, demikian sebaliknya semakin minimnya pengetahuan karyawan akan K3 maka semakin besar resiko terjadinya kecelakaan kerja.

Terjadinya kecelakaan kerja dimulai dari disfungsi manajemen dalam upaya penerapan keselamatan dan kesehatan kerja (K3). Ketimpangan tersebut menjadi penyebab dasar terjadinya kecelakaan kerja. Dengan semakin meningkatnya kasus kecelakaan kerja dan kerugian akibat kecelakaan kerja, serta meningkatnya potensi bahaya dalam proses produksi, dibutuhkan pengelolaan K3 secara efektif, menyeluruh, dan terintegrasi dalam manajemen perusahaan. Manajemen K3 dalam organisasi yang efektif dapat membantu untuk meningkatkan semangat pekerja dan memungkinkan mereka memiliki keyakinan dalam pengelolaan organisasi (Akpan, 2011).

Kasus kecelakaan dan gangguan kesehatan akibat kerja menunjukkan, bahwa jumlah kecelakaan yang terjadi pada tahun 2012 sebanyak 105.846 kasus, pada tahun 2013 sebanyak 95.418 kasus, pada tahun 2014 sebanyak 96.081 kasus, pada tahun 2015 terjadi kecelakaan sebanyak 70.069 kasus kecelakaan kerja dan sepanjang tahun 2016 telah terjadi kecelakaan kerja sebanyak 65.474 kejadian. Data tersebut dapat menjadi tolak ukur pencapaian perilaku di Indonesia (Tarwaka, 2017)

Hal ini terdapat dari kasus kecelakaan kerja yang berakibat pada meninggalnya tenaga kerja. Data BPJS Ketenagakerjaan menggambarkan penurunan kecelakaan kerja dari 110.285 kasus di 16.082 perusahaan dari 296.271 perusahaan yang terdaftar dengan korban meninggal dunia 530 orang pada tahun 2015, menjadi 101.367 kasus di 17.069 perusahaan dari 359.724 perusahaan yang terdaftar dengan korban meninggal dunia sebanyak 2.382 orang sampai dengan bulan November tahun 2016. (Hanif, 2016).

Dalam kegiatan pelaksanaan pekerjaan dan dukungan penerbangan sehari hari personil TNI Agkatan Udara Maimun Saleh harus mengedepankan Safety dan dalam hal ini penulis membuat 
sebuah penelitian dimana Faktor yang berhubungan dengan kesadaran dan kedisiplinan personil TNI angkatan Udara Maimun Saleh dalam menjaga keselamatan dan Kesehatan kerja dalam bertugas. (Progja TNI AU Lanud Mimun Saleh, 2017)

Dalam pelaksanaan tugas sehari hari personil Lanud serta karyawan Bandara Maimun Saleh baik dalam bekerja maupun dalam mendukung kegiatan penerbangan sering menggunakan mesin ataupun peralatan yang dapat menimbulkan potensi bahaya yang dapat mengancam kesehatan dan keselamatan pekerjanya.diantaranya bising, paparan panas, debu, dan benda logam lainnya. Pengabaian aspek kesehatan dan keselamatan kerja dalam suatu proses pelaksanaan pekerjaan dapat menimbulkan penurunan kinerja dan bahkan mengakibatkan kerugian yang dampaknya bukan hanya instansi tetapi juga personil ataupun karyawan itu sendiri, oleh karena itu perlu pengawasan. (Progja TNI AU Lanud Mimun Saleh, 2017).

Dari data diatas masih adanya kasus kecelakaan maupun kecelakaan kerja , hal ini tentu saja harus dapat menjadi perhatian dari manajemen kesehatan dan keselamatan kerja di Lanud Maimun Saleh agar dapat meminimalisir lagi kasus terjadinya kecelakaan maupun penyakit yang diakibatkan oleh kelalaian dan lingkungan kerja sehingga kesehatan setiap personil dapat terpelihara dengan baik.

\section{METODE PENELITIAN}

Penelitian ini adalah penelitaan deskriftif analitik dengan pendekatan Cross Sectional, Penelitian telah dilakukan dilingkungan Lanud Maimun Saleh Sabang pada tanggal 22 s/d 25 November 2017. pengambilan sampel menggunakan tekhnik total sampling yaitu seluruh personal Lanud Maimun Saleh sebanyak 47 orang.

\section{HASIL DAN PEMBAHASAN}

Tabel 1: Distribusi Frekuensi Faktor yang Berhubungan dengan Kesadaran Keselamatan dan Kesehatan Kerja di Lingkungan Lanud Maimun Saleh Sabang

\begin{tabular}{lcc}
\hline \multicolumn{1}{c}{ Variabel } & Frekuensi & Persentase (\%) \\
\hline Kesadaran personil terhadap K3 & & \\
$\quad$ Rendah & 20 & 42,6 \\
$\quad$ Tinggi & 27 & 57,4 \\
Perilaku & & 46,8 \\
$\quad$ Negatif & 22 & 53,2 \\
$\quad$ Positif & 25 & \\
Lingkungan & & 38.3 \\
$\quad$ Kurang Baik & 18 & 61.7 \\
$\quad$ Baik & 29 & \\
\hline
\end{tabular}


Berdasarkan Tabel 1 menunjukkan bahwa dari 47 responden, sebagian besar responden dengan kesadaran personil terhadap keselamatan dan keseahatan kerja yang tinggi sebanyak 27 orang $(57,4 \%)$, sebagian besar responden dengan perilaku positif sebanyak 25 orang $(53,2 \%)$, sebagian besar responden dengan lingkungan kerja baik sebanyak 29 orang $(61,7 \%)$.

Tabel 2: Hubungan Perilaku dengan Kesadaran Keselamatan dan Kesehatan Kerja di Lingkungan Lanud Maimun Saleh Sabang

\begin{tabular}{|c|c|c|c|c|c|c|c|}
\hline \multirow{3}{*}{ Perilaku } & \multicolumn{4}{|c|}{ Kesadaran K3 } & \multirow{2}{*}{\multicolumn{2}{|c|}{ Total }} & \multirow{3}{*}{$p$ value } \\
\hline & \multicolumn{2}{|c|}{ Rendah } & \multicolumn{2}{|c|}{ Tinggi } & & & \\
\hline & $\mathbf{n}$ & $\%$ & $\mathbf{n}$ & $\%$ & n & $\%$ & \\
\hline Negatif & 15 & 68.2 & 19 & 7 & 31.8 & 100 & ברחת \\
\hline Positif. & 5 & 20 & 34 & 20 & 80 & 100 & 0.002 \\
\hline
\end{tabular}

Berdasarkan tabel 2 menunjukan bahwa dari 25 responden yang berprilaku positif (80\%) tinggi terhadap kesadaran keselamatan dan kesehatan kerja, lebih besar dibandingkan dengan yang prilaku negatif yaitu (31,8\%). Hasil uji chi-square diperoleh p value $=0,002$. Sehingga dapat disimpulkan bahwa $\mathrm{p}<0,05$ yang artinya $\mathrm{Ha}$ diterima atau ada hubungan antara prilaku dengan kesadaran keselamatan dan kesehatan kerja di lingkungan Lanud Maimun Saleh Sabang.

Tabel 3: Hubungan Lingkungan Kesadaran Keselamatan dan Kesehatan Kerja di Lingkungan Lanud Maimun Saleh Sabang

\begin{tabular}{|c|c|c|c|c|c|c|c|}
\hline \multirow{3}{*}{ Lingkungan } & \multicolumn{4}{|c|}{ Kesadaran K3 } & \multirow{2}{*}{\multicolumn{2}{|c|}{ Total }} & \multirow{3}{*}{ p value } \\
\hline & \multicolumn{2}{|c|}{ Rendah } & \multicolumn{2}{|c|}{ Tinggi } & & & \\
\hline & $\mathbf{n}$ & $\%$ & $\mathbf{n}$ & $\%$ & $\mathbf{n}$ & $\%$ & \\
\hline Kurang Baik & 12 & 66.7 & 6 & 33.3 & .18 & 100 & \multirow{2}{*}{0.020} \\
\hline Baik & 8 & 27.6 & 21 & 72,4 & 29 & 100 & \\
\hline
\end{tabular}

Berdasarkan tabel 3 menunjukan bahwa dari 29 responden yang lingkungan baik $(72,4 \%)$ tinggi terhadap kesadaran keselamatandan kesehatan kerja, lebih besar dibandingkan dengan lingkungan kurang baik yaitu (33,3\%). Hasil uji chi-square diperoleh $\mathrm{p}$ value $=0,020$. Sehingga dapat disimpulkan bahwa $\mathrm{p}<0,05$ yang artinya Ha diterima atau ada hubungan antara lingkungan dengan kesadaran keselamatan dan kesehatan kerja di lingkungan Lanud Maimun Saleh Sabang.

\section{Hubungan prilaku dengan Kesadaran Keselamatan dan Kesehatan Kerja}

Berdasarkan tabel 2 menunjukan bahwa dari 25 responden yang berprilaku positif (80\%) tinggi terhadap kesadaran keselamatan dan kesehatan kerja, lebih besar dibandingkan dengan yang prilaku negatif yaitu $(31,8 \%)$. Hasil uji chi-square diperoleh $\mathrm{p}$ value $=0,002$. Sehingga dapat 
disimpulkan bahwa $\mathrm{p}<0,05$ yang artinya Ha diterima atau ada hubungan antara prilaku dengan kesadaran keselamatan dan kesehatan kerja di lingkungan Lanud Maimun Saleh Sabang.

Hasil penelitian ini sejalan terhadap penelitian yang pernah dilakukan oleh Iwan Kesuma, (2016) yang berjudul faktor-faktor yang mempengaruhi keselamatan dan Kesehatan Kerja Karyawan Pt London Sumatera Tbk Kebun Bungara", terdapat pengaruh antara prilaku dengan keselamatan dan kesehatan kerja diperoleh nilai nilai p-value $(0,001)$.

Perilaku manusia dalam bekerja dapat menciptakan munculnya risiko yang berkaitan dengan keselamatan kerja. Perilaku yang tidak aman dianggap sebagai hasil dari kesalahan yang dilakukan baik oleh pekerja yang terlibat secara langsung. faktor perilaku merupakan aspek manusia dan faktor tersebut lebih sedikit diperhatikan dari faktor lingkungan. Perilaku tidak aman (unsafe behavior) merupakan penyebab dasar pada sebagian besar kejadian hampir celaka dan kecelakaan di tempat kerja. Oleh karena itu, perlu dilakukan observasi mendalam terhadap kalangan pekerja mengenai perilaku kerja tidak aman. Umpan balik mengenai observasi terhadap perilaku telah terbukti sukses dalam mengurangi perilaku tidak aman para pekerja. Umpan balik yang diberikan dapat berupa lisan, grafik, table dan bagan, atau melalui tindakan perbaikan (Wibisono, 2013).

Menurut Griffin dan Neal (2012), kinerja keselamatan dibedakan menjadi dua tipe yaitu safety compliance dan safety participant. Safety compliance digambarkan sebagai aktivitasaktivitas inti yang perlu dilaksanakan oleh individu-individu untuk memelihara keselamatan di tempat kerja, seperti mengikuti standar prosedur kerja dan menggunakan alat pelindung diri dengan baik. sedangkan safety participant digambarkan sebagai perilaku yang tidak secara langsung berkontribusi kepada keselamatan individu tetapi dapat membantu mengembangkan suatu lingkungan yang mendukung keselamatan, seperti secara sukarela berpartisipasi dalam aktivitasaktivitas keselamatan.

Menurut Tarwaka (2015), setiap organisasi perusahaan memiliki pendekatan yang berbedabeda dalam penerapan perilaku K3 di tempat kerjanya, tetapi sebagian besar pendekatan yang digunakan pada prinsipnya sangat fleksibel, dan dapat disesuaikan dengan jenis organisasi perusahaan dan situasi yang terjadi di perusahaan masing-masing.

Menurut asumsi peneliti dapat disimpulkan bahwa dari hasil penelitian yang teliti terdapat hubungan antara prilaku dengan kesadaran keselamatan dan kesehatan kerja, disebabkan dengan adanya prilaku positif personil lebih memikirkan tentang kerugiannya dan di saat bertugas agar menghindari dari larangan yang sudah ditetapkan di Lanud Maimun Sabang, supaya tidak terjadi yang tidak dinginkannya. Dengan adanya prilaku individu maka personil dapat memelihara keselamatan di tempat kerja, seperti mengikuti standar prosedur kerja dan menggunakan alat pelindung diri dengan baik. 


\section{Hubungan Lingkungan dengan Kesadaran Keselamatan dan Kesehatan Kerja}

Berdasarkan tabel 3 menunjukan bahwa dari 29 responden yang lingkungan baik $(72,4 \%)$ tinggi terhadap kesadaran keselamatan dan kesehatan kerja, lebih besar dibandingkan dengan lingkungan kurang baik yaitu $(33,3 \%)$. Hasil uji chi-square diperoleh p value $=0,020$. Sehingga dapat disimpulkan bahwa $\mathrm{p}<0,05$ yang artinya Ha diterima atau ada hubungan antara lingkungan dengan kesadaran keselamatan dan kesehatan kerja di lingkungan Lanud Maimun Saleh Sabang. Hasil penelitian ini sejalan terhadap penelitian yang pernah dilakukan oleh Iwan Kesuma, (2016) yang berjudul faktor-faktor yang mempengaruhi keselamatan dan Kesehatan Kerja Karyawan Pt London Sumatera Tbk Kebun Bungara”, terdapat pengaruh antara lingkungan kerja dengan keselamatan dan kesehatan kerja diperoleh nilai nilai p-value $(0,001)$.

Keselamatan kerja menyangkut segenap proses perlindungan tenaga kerja terhadap kemungkinan adanya bahaya yang timbul dalam lingkungan pekerjaan. ada faktor yang mempengaruhi keselamatan kerja sehingga berakibat terhadap kecelakaan kerja ,kesehatan kerja menyangkut kesehatan fisik dan mental, Kesehatan mencakup seluruh aspek kehidupan manusial termasuk lingkungan kerja, dan ada juga beberapa faktor-faktor yang mempengaruhi kesehatan kerja antara lain: Kondisi lingkungan tempat kerja Kondisi ini meliputi Kondisi Fisik Berupa penerangan, suhu udara, ventilasi ruangan tempat kerja, tingkat kebisingan, getaran mekanis, radiasi dan tekanan udara .Kondisi Fisiologis Kondisi ini dapat dilihat dari konstruksi mesin/peralatan, sikap badan dan cara kerja dalam melakukan pekerjaan, hal-hal yang dapat menimbulkan kelelahan fisik dan bahkan dapat mengakibatkan perubahan fisik tubuh karyawan. Kondisi khemis kondisi yang dapat dilihat dari uapgas, debu, kabut, asap, awan, cairan dan benda padat. Mental Psikologis Kondisi ini meliputi hubungan kerja dalam kelompok/teman sekerja, hubungan kerja antara bawahan dan atasan dan sebaliknya, suasana kerja. (Swasto,2011).

Lingkungan adalah tempat berkembanganya perilaku terhadap kebiasaan yang ada di lingkungan. Lingkungan yang kurang baik akan berpengaruh pada perkembangan jiwa seseorang. Hal-hal yang tidak baik yang diterimanya dalam interaksi menjadi hal yang biasa baginya. Lingkungan yang tidak baik dapat mempengaruhi seseorang untuk melanggar norma-norma yang ada di dalam masyarakat.

Menurut asumsi peneliti dapat disimpulkan bahwa dari hasil penelitian yang teliti terdapat hubungan antara lingkungan dengan kesadaran keselamatan dan kesehatan kerja, lingkungan sangat yang baik sangat berpengaruh terhadap personil dengan kesadaran disaat berfikir sesuatu yang lebih baik, dikarenakan lingkungan merupakan tempat berkembanganya perilaku terhadap kebiasaan yang ada di lingkungan, dengan kesadaran juga juga memberikan kemampuan kepada manusia untuk belajar dari masa lalu, agar dapat mengantisipasi hal-hal yang akan terjadi dimasa 
akan datang.dan dapat mempertahankan diri dari ancaman serta mengembangkan diri dari lingkungan kerjanya.

\section{KESIMPULAN}

1. Ada hubungan antara prilaku dengan kesadaran keselamatan dan kesehatan kerja di lingkungan Lanud Maimun Saleh Sabang, dengan diperoleh nilai $\mathrm{p}=0,002$.

2. Ada hubungan antara lingkungan dengan kesadaran keselamatan dan kesehatan kerja di lingkungan Lanud Maimun Saleh Sabang, dengan diperoleh nilai $\mathrm{p}=0,020$.

\section{SARAN}

1. Bagi Institusi Pendidikan

Diharapkan penelitian ini dapat menjadi bahan masukan bagi dosen pengajar dalam membimbing dan menambah pengetahuan mahasiswi Program Studi Kesehatan Masyarakat Universitas Ubudiyah Indoensia mengenai faktor yang berhubungan dengan kesadaran keselamatan dan kesehatan kerja di lingkungan Lanud Maimun Saleh Sabang.

2. Bagi Tempat Penelitian

Diharapkan penelitian ini dapat memberikan informasi kepada personilnya agar berhati-hati dalam menjaga dirinya keselematan dan kesehatan kerja.

3. Bagi Peneliti Selanjutnya

Diharapkan penelitian ini dapat menjadi bahan masukan dalam meningkatkan keterampilan peneliti selanjutnya yang ingin meneliti tentang faktor yang berhubungan dengan kesadaran keselamatan dan kesehatan kerja, terhadap variabel dan desain yang berbeda untuk hasil yang lebih baik lagi.

\section{DAFTAR PUSTAKA}

Akpan,.(2011). Effective Safety and Health Management Policy for Improved Performance of Organizations in Africa, International Journal of Business and Management. Vol. 6, No. 3, University of Calabar, Nigeria.

Griffin, M. A., dan Neal, A. (2012). Safety Climate An Safety Behavior. Australian Journal Of Management Vol 27.

Hanif, (2011). Tingkatkan Kualitas Hidup Manusia Menuju Masyarakat yang Selamat, Sehat dan Produktif https://www.proxsisgroup.com

Iwan Kesuma (2016) Analisis Faktor-Faktor Yang Mempengaruhi Keselamatan Dan Kesehatan Kerja Karyawan P London Sumatera Tbk Kebun Bungara.

Swasto, (2011). Manajemen Sumber Daya Manusia, Malang, UB Press.

Smith dan Sonesh (2011). How Hazards and Safety Training Influence Learning and Performance, Journal of Applied Psychology 2011 American

Psychological 
Association Vol.96, No.1, 46-70 0021-9010/11/\$12.00

DOI:10.1037/a0021838,Tulane University, Amerika

ProgjaTNI AU Lanud Mimun Saleh, (2017). Profil Progja Sikes Lanud Maimun Saleh. Kota Sabang

Tarwaka. (2017). Manajemen dan Implementasi K3 di Tempat Kerja. Surakarta: Harapan Press

Wibisono, Bayu. (2013). Faktor-Faktor yang Berhubungan Dengan Kejadian Kecelakaan Kerja Pada Pekerja Tambang Pasir Gali di Desa Pengiringan Kabupaten Pemalang Tahun 2013. Universitas Dian Nuswantoro. Semarang. Skripsi 